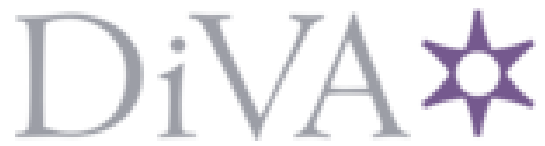

http://www.diva-portal.org

Preprint

This is the submitted version of a paper published in Environmental Microbiology.

Citation for the original published paper (version of record):

Wedin, M., Maier, S., Fernández-Brime, S., Cronholm, B., Westberg, M. et al. (2016)

Microbiome change by symbiotic invasion in lichens

Environmental Microbiology, 18: 1428-1439

https://doi.org/10.1111/1462-2920.13032

Access to the published version may require subscription.

N.B. When citing this work, cite the original published paper.

Permanent link to this version:

http://urn.kb.se/resolve?urn=urn:nbn:se:nrm:diva-1297 
1 Environmental Microbiology

\section{Microbiome change by symbiotic invasion in lichens}

3

4 Wedin, Mats ${ }^{1,4^{*}}$, Maier, Stefanie ${ }^{2,4}$, Fernandez-Brime, Samantha ${ }^{1}$, Cronholm, Bodil ${ }^{3}$,

5 Westberg, Martin ${ }^{1}$ and Grube, Martin ${ }^{2}$

6

$7 \quad{ }^{1}$ Department of Botany, Swedish Museum of Natural History, P.O. Box 50007, SE-104 05

8 Stockholm, Sweden

$9 \quad{ }^{2}$ Institute of Plant Sciences, University of Graz, Holteigasse 6, A-8010 Graz, Austria

$10{ }^{3}$ Department of Bioinformatics and Genetics, Swedish Museum of Natural History, P.O. Box

11 50007, SE-104 05 Stockholm, Sweden

$12{ }^{4}$ These authors share first authorship

13 *For correspondence. E-mail: mats.wedin@nrm.se; Tel. (+46) 85195 5194; Fax (+46) 85195

$14 \quad 4221$

15

16 Running title: Microbiome change by symbiotic invasion in lichens

17

18

19 


\section{Summary}

21 Lichens are obligate symbioses between fungi and green algae or cyanobacteria. Most lichens resynthesize their symbiotic thalli from propagules, but some develop within the structures of already existing lichen symbioses. Diploschistes muscorum starts as a parasite infecting the lichen Cladonia symphycarpa, and gradually develops an independent Diploschistes lichen thallus. Here we studied how this process influences lichen associated microbiomes and photobionts by sampling four transitional stages, at sites in Sweden and Germany, and characterizing their microbial communities using high-troughput 16S rRNA genes and photobiont-specific ITS rDNAsequencing, and fluorescence in situ hybridization. A gradual microbiome shift occurred during the transition but fractions of Cladonia-associated bacteria were retained during the process of symbiotic reorganization. Consistent changes observed across sites included a notable decrease in relative abundance of Alphaproteobacteria with a concomitant increase in Betaproteobacteria. Armatimonadia, Spartobacteria, and Acidobacteria also decreased during the infection of Cladonia by Diploschistes. The lichens differed in photobiont specificity. Cladonia symphycarpa was associated with the same algal species at all sites but Diploschistes muscorum had a flexible strategy with different photobiont combinations at each site. This symbiotic invasion system suggests that partners can be reorganized and selected for maintaining potential roles rather than depending on particular species. 


\section{Introduction}

41 Lichens are obligate symbioses between fungi and green algae or cyanobacteria, resulting in the production of a joint phenotype unique among microbial symbioses, the lichen thallus. Within the protective association of the lichen thallus, the fungal and algal components have been able to extend their range of ecological niches considerably and sustain much more exposed and stressful habitats compared with their free-living, non-symbiotic relatives. While many lichens represent classic examples of mutualistic symbioses, it has been suggested that lichens are better viewed as an analogy to human crop domestication, where fungi cultivate the algal constituent (Lücking et al., 2009). A number of reviews on lichens as symbiotic systems, their component diversity, physiology, metabolism, contributions to ecosystems and environmental roles, can be found in Nash (2008).

In addition to the fungal symbiont, many species of other fungi can inhabit the lichen thalli and interact with their hosts in different ways, ranging from commensalism to parasitism. More than 1800 species of lichenicolous (lichen-inhabiting) fungi are known to science (Lawrey and Diederich, 2003), and rather than representing a single phylogenetic group, they are scattered in many unrelated fungal lineages. Many lichenicolous fungi are closely related to lichens, and were also suggested as a first stage of de-lichenization towards the evolution of other fungal lifestyles (Lutzoni et al., 2001). In reality, many lichenicolous fungi have the same type of relationship with their host algae as the host lichen fungus itself, and may better be viewed as lichens, irrespective of if they form an independent thallus within or on the surface of the host thallus (Rambold and Triebel, 1992). Lichenicolous lichens, which establish their own mutualistic thallus, grow within the limits of their host's structures, sometimes forming rather small areas of infection. For other species, parasitism is only a transient stage of early development. Such parasites require infecting other lichens before continuing as independent mutualistic symbioses. The host lichen is often destroyed and the 
lichenicolous fungus takes advantage of the algae available in the host thallus. This established photobiont can be directly accessed without wasting energy to capture and grow a new algal population. Thus lichenicolous behaviour can provide a starting benefit for parasitic lichens, as in Rimularia insularis where maintenance of the host's algae was observed by de los Rios et al. (2002). This, however, is not always the case. One example is Diploschistes muscorum, a common species in lichen-dominated biological soil crusts which infects lichens of the genus Cladonia (Fig. 1). Friedl (1987) found that Diploschistes starts as a lichenicolous fungus, invading the Cladonia thallus and utilizing the alga at an intermediate stage. Then Diploschistes replaces the Cladonia photobiont with a more suitable alga, together with which it forms an independent free-living Diploschistes thallus. The process in which horizontal transfer of algal partners occurs among fungal lineages was referred to as algal switching (Piercey-Normore and DePriest 2001). The photobiont switch in D. muscorum may indicate that the mycobiont has a moderate selectivity level, as it can establish symbiosis with two different algal species. And while several studies have examined established photobiont communities in Diploschistes and host Cladonia thalli (Bačkor et al. 2010, Škaloud and Peksa 2010, Škaloud et al. 2015), to the best of our knowledge, none have investigated the photobiont switching process with the Diploschistes take-over of Cladonia. Bacterial groups, such as Alphaproteobacteria and Acidobacteria, have been consistently recovered from lichen thalli (Cardinale et al., 2008; Grube et al., 2012; Muggia et al., 2013), and evidence is rapidly accumulating that these microbes may generally play integral roles in the lichen symbiosis (Grube et al., 2009, 2015; Hodkinson and Lutzoni, 2009; Bates et al., 2011; Printzen et al., 2012; Erlacher et al., 2015). Other complex community interactions between symbiotic microbes and eukaryotes are of course well-known, for example, among marine sponges or within animal guts (Webster, 2014). Microbial spatial localization patterns in multispecies associations may further reflect conditions as substrate 
concentration gradients, or biotic interactions as microbial coaggregation or resource competition (Daims and Wagner, 2011). Little is known, however, about community and spatial changes that occur in microbiomes during lichen-to-lichen parasitization-takeover events. Considering that previous studies suggest lichens maintain species-specific microbial communities (Grube et al., 2009; Bates et al., 2011), it is reasonable to expect marked microbiome shifts as one lichen species infects, and eventually overcomes, another. In order to address this knowledge gap, we investigated lichen microbiome dynamics as the parasitic lichen Diploschistes muscorum takes over Cladonia symphycarpa using high-throughput 16S rRNA gene and photobiont-specific ITS rDNA sequencing to track bacterial and algal transitions during the infection process, and employed fluorescence in situ hybridization (FISH) to localize bacteria in the Cladonia and Diploschistes lichen thalli.

\section{Results}

Four stages in the Cladonia-Diploschistes transition were sampled with three replicates each on the three study sites (Gynge and Dröstorp in Öland, Sweden, and Gössenheim in Bavaria, Germany): A) Cladonia with no visible infection, B) early infection stage defined by the first visible Diploschistes thallus, C) late-stage infection with parts of the Cladonia thallus still identifiable, and D) final stage with only a fully developed Diploschistes thallus (Fig. 1A-D).

\section{Richness, diversity and taxonomic composition of bacterial communities}

We tested for differences in bacterial richness (number of operational taxonomic units, OTUs, at $97 \%$ similarity level) and evenness across infection stages. There were no differences in number of bacterial OTUs when rarefied to 1010 sequences per stage (two sample $t$-test, $p>$ 0.05), and stages did not differ in estimated richness (Chao 1 index, two sample $t$-test, $p>$ 0.05), and there was no general trend in evenness or phylogenetic diversity between stages 
115 (Shannon index and Faith's Phylogenetic Diversity, two sample $t$-test, $p>0.05$ for both). The

116 16S rDNA amplicon survey revealed (Fig. 2A) the dominance of Proteobacteria (57.2\%,

117 percentages here and elsewhere are averages across all samples), Bacteroidetes (12.1\%),

118 Acidobacteria (11.0\%), Actinobacteria (5.8\%) and Verrucomicrobia (3.7\%) in the system.

119 Several other phyla, including Chloroflexi, Planctomycetes, Armatimonadetes and

120 Cyanobacteria, with relative abundances less than $4 \%$ of the $16 \mathrm{~S}$ rRNA reads, were present,

121 possibly (at least Cyanobacteria) as casual epiphytes. At class level Alphaproteobacteria (37.1

$122 \%)$, Betaproteobacteria (17.1\%), Saprospirae (6.2\%), Actinobacteria (4.7 \%) and

123 Acidobacteria (4.4\%) were main contributors. Alphaproteobacteria were primarily

124 represented by the orders Rhodospirillales (19.0\%; Acetobacteraceae, Rhodospirillaceae) and

125 Rhizobiales (7.9\%; Methylobacteriaceae, Beijerinckiaceae, Bradyrhizobiaceae,

126 Methylocystaceae), and Betaproteobacteria by Burkholderiales (16.7 \%; Burkholderiaceae,

127 Oxalobacteraceae). Among the Saprospirae, Saprospirales (6.2\%) and Cytophagales (3.4\%)

128 were predominant. Abundant and frequently occurring members across stages were identified

129 with the two-parameter model by Li et al. (2013) taking into account taxonomic abundance

130 and ubiquity for each taxon. Eight members at family level were identified at the ubiquity cut-

131 off of $80 \%$ and abundance cut-off of $1 \%$ (Fig. 2B).

132

133 Beta diversity patterns determined using NMDS

134 The samples of the four infection stages formed no clear clusters based on the Bray-Curtis

135 dissimilarity metric but clustered separately (Fig. S1) when community differences were

136 measured using unweighted and weighted UniFrac distance metrics. Although samples of

137 stage B (initial infection) overlapped with Cladonia samples, while samples of stage C

138 (progressed infection) overlapped with Diploschistes samples, ANOSIM test showed no

139 significance for sample type (stage A-D; ANOSIM analyses of unweighted UniFrac distances 

$R=0.11, p>0.05$, ANOSIM of weighted UniFrac $R=0.15, p>0.05)$. The ordination of

141 bacterial community structure data revealed that the main structuring factor was sampling site

142 (ANOSIM analyses of unweighted UniFrac distances $R=0.43, p=0.007$, ANOSIM of

143 weighted UniFrac $R=0.35, p=0.035$ ). As no consistent differences between the four stages

144 were observed in the general bacterial community structure, we assessed the common and

145 unique OTUs (Fig. 3A) and changes in abundance of bacterial taxa in the process of

146 Diploschistes infection. Of the 1295 observed OTUs, only $9.1 \%$ were present in all four

147 infection stages (Fig. 3A). The main changes at higher levels included incremental increases

148 and decreases in the process of infection and distinct maxima at particular infection stages.

149 Armatimonadia (1.7\% in stage A to $0.5 \%$ in stage D), Spartobacteria (6.1\% in stage A to 0.8

$150 \%$ in stage D), Acidobacteria (6.4\% in stage A to $1.3 \%$ in stage D) and Alphaproteobacteria

151 (52.3\% in stage A to $18.2 \%$ in stage D) were more abundant at all sites; whereas

152 Betaproteobacteria increased gradually in relative abundance in the process of infection.

153 Orders with similar patterns at more than one location are shown in Fig. 3B. Although taxa at 154 class and order level showed similar dynamics at all sites, their relative abundance within the 155 bacterial communities was variable. We used the LEfSe tool to identify 16 bacterial taxa at 156 order level and 21 at family level where relative abundance changes differed significantly 157 between stages. The Diploschistes samples of all sites differed from the other infection stages 158 in their higher abundances of Burkholderiales and Clostridiales (Fig. 3C).

160 Fluorescence in situ hybridization and confocal laser scanning microscopy

161 As the relative abundance of Alphaproteobacteria and Betaproteobacteria changed in the 162 transition, taxonomic group-specific oligonucleotide probes were applied in fluorescence in 163 situ hybridization (FISH). Consistent with this finding was the observation of 164 Alphaproteobacteria-specific signals with 16S rRNA - FISH in Cladonia and 
165 Betaproteobacteria-specific signals in Diploschistes (Fig. 4). Bacteria were visible at the

166 upper cortex and the lower surface of $C$. symphycarpa (Fig. 4A-D), but no bacteria were 167 attached to the algal layer or medulla. In Diploschistes (Fig. 4E), FISH-CLSM revealed a low 168 over-all density of bacteria (confirmed by light microscopy) suggesting a lower abundance 169 compared with Cladonia.

Photobionts present in Cladonia and Diploschistes

172 All Cladonia symphycarpa samples contained a single photobiont (Asterochloris) at all three sites. Diploschistes muscorum, however, had different photobionts at each site. At one site Diploschistes was associated with the same Asterochloris species as the Cladonia. At another 175 site the Diploschistes samples were all associated with a Trebouxia only, possibly following a 176 similar development and photobiont replacement as described by Friedl (1987). The most complicated mycobiont-photobiont relationship was found at the third site, where Diploschistes was associated with at least three different algae. All samples had the Trebouxia

179 photobiont but, in addition, one sample still contained the initial Asterochloris present in $C$.

180 symphycarpa, and two samples had Dictyochloropsis symbiontica as a second photobiont.

181 The photobiont topologies resulting from the Maximum Likelihood analyses (Figs. S2-S4)

182 were more resolved than from the Bayesian analyses, whereas the Bayesian trees were better 183 supported. The topologies recovered were in agreement.

\section{Discussion}

186 To the best of our knowledge, this is the first study to report on bacterial community 187 transitions that occur when one lichen species is parasitically invaded by another. The 188 bacterial community of Cladonia symphycarpa is replaced by a different community when 189 Diploschistes muscorum infects and eventually replaces the Cladonia thallus. This transition 
190 is gradual, with younger infections having a bacterial composition resembling the uninfected

191 Cladonia community dominated by Alphaproteobacteria (Fig. 2A, 3B, 4). More advanced

192 infections are more similar to the Diploschistes bacterial community even if these still retain

193 fractions of Cladonia-associated bacteria. One recent study investigated effects of a fungal

194 infection on the bacterial communities in lichens, Rhagadostoma lichenicola on Solorina

195 crocea in the Eastern Alps (Grube et al., 2012). Similar to other non-lichenized lichenicolous

196 fungi, this species merely develops unstratified hyphal structures inside the host. Grube et al.

197 (2012) found that the microbiome composition at phylum level remained largely the same,

198 irrespective of the infection status of the host. Differences were only found at bacterial strain

199 level. In contrast, in the present study we see clear differences at higher taxonomic levels,

200 which correlate with the formation of a genuine symbiotic phenotype by the infecting fungus.

201 The Diploschistes infection causes successive breakdown of the structural integrity of

202 Cladonia and degradation of its hyphae. It is, however, hardly possible to quantify the extent

203 of breakdown of individual hyphae and as we never found an enrichment of generalist

204 decomposers, we interpret this thallus replacement and takeover as a process without a phase

205 of unspecific bacterial decomposition. Instead a distinct but gradual shift in the bacterial

206 community was observed when one lichen replaces another through parasitism. This

207 observation corroborates previous indications of host specific composition of lichen-

208 associated microbiota (Grube et al., 2009; Bates et al., 2011). Moreover, the changes here

209 occur in similar habitats with similar microclimate, and also proceed similarly when

210 comparing samples originating from geographically distant sites. The results also suggest that

211 the more homogeneous bacterial community in the attacked symbiosis is replaced with more

212 varied microbiota in the parasite, as differences are found across the sampling sites. The

213 higher variation of the bacterial communities in the parasite is paralleled by its broader

214 compatibility with different algae. The most obvious change in the transition is that the 
Alphaproteobacteria dominating the Cladonia community decrease, at all sites.

216 Betaproteobacteria of the Burkholderiales increase substantially when Diploschistes takes

217 over, at two of the three sites. This increase is partly due to Oxalobacteraceae, a group known

218 to occur in lichens (Lang et al., 2007). As members of this group are involved in oxalate

219 degradation, this increase could be correlated with the substantial production of Ca-oxalate in 220 Diploschistes thalli that is apparent from our own observations of microscopic sections. The 221 decline of Alphaproteobacteria was due mostly to the loss of Rhodospirillales,

222 Caulobacteriales and Sphingomonadales, while notably the relative abundance of lichenassociated Rhizobiales (LAR1), a clade of bacteria so far known only from lichens (Hodkinson and Lutzoni, 2009; Bates et al., 2011) did not change significantly in the course of infection. Changes were not consistent across all sites, an increase in Actinobacteria was observed at two sites (2.3 \% to $6.7 \%$ at Dröstorp and $1.6 \%$ to $10.7 \%$ at Gössenheim). While the Alphaproteobacteria did significantly decrease in samples from the Dröstorp site, the corresponding increase in Betaproteobacteria was not as evident, instead by the final stage there was a significant increase in the abundance of Chloroflexi $(13.1 \%$ of all sample sequences on average), a group with low representation $(2.0 \%)$ at other sites for all stages. The coexistence and interactions of bacteria and fungi have been observed in several environments and comprise polymicrobial communities to symbiotic associations of fungal hyphae and bacterial cells, for example mycorrhiza helpers. Bacteria aid in mycorrhiza pathogens (Frey-Klett et al., 2007) and communities associated with mycorrhiza are specific 236 for the plant host (de Boer et al., 2005; Frey-Klett and Garbaye, 2005; Frey-Klett et al., 2011). Lichen-associated bacteria contribute to similar beneficial functions for the host

238 (Grube et al., 2009, 2015; Erlacher et al., 2015) and communities contributing functions to 239 maintenance of symbiotic integrity are apparently adjusted to the fungal determined 
architecture. Here, we found a number of taxonomic groups with nitrogen-fixing members,

241 including Rhodospirillales and Rhizobiales, indicating that bacterial associates may contribute

242 to lichen nitrogen requirements, as was suggested previously (Hodkinson and Lutzoni, 2009;

243 Bates et al., 2011). Interestingly, the observed decline of Acetobacteriaceae in the

244 Alphaproteobacteria was parallelled by a relative increase of Burkholderia, some of which are 245 also able to fix nitrogen.

The two lichens studied clearly differ in physical parameters of their thallus structure, in particular the thallus surfaces differ in hydrophily. While the leafy scales of Cladonia symphycarpa have hydrophilic surfaces, where water droplets are easily percolating into the thallus, Diploschistes has hydrophobic surfaces, where droplets may persist much longer on the surface due to acetone-insoluble molecules (Lange et al., 1997). We assume that these 251 differences in host structure are major factors determining bacterial composition, as bacteria respond differently to water accessibility. A close association of bacteria (Rhizobiales) with the hydrophilic fungal cortex of Lobaria was found by Erlacher et al. (2015). In reindeer lichens, Cardinale et al. (2008) showed that the hydrophilic interior surfaces of the cylindric branches were inhabited by a bacterial biofilm, whereas the hydrophobic external surfaces of the thalli were hardly colonized. It is therefore likely that the surface hydrophobicity of Diploschistes impedes substantial bacterial aggregation here (Fig. 4E). The lichens further differ in their extracellularly deposited secondary chemistry: D. muscorum producing diploschistesic acid, sometimes with lecanoric acid, whereas $C$. symphycarpa contains 260 atranorin and norstictic acids. Potential effects of secondary lichen metabolites on the growth 261 on certain bacteria are known from culture assays (see review of Boustie and Grube, 2005).

262 Thus, differences of thallus chemistry may also affect the composition of bacterial 263 communities. It can also be argued whether bacteria enriched in the course of infection could 
have both a detrimental effect on Cladonia and a beneficial effect on Diploschistes. The

pending tests of such hypotheses would require thoughtful experimental approaches.

Our survey of algal photobionts over the course of the infection and eventual take-over of Cladonia by Diploschistes suggests a progression from a restricted photobiont maintenance in the host to a more generalist photobiont strategy by the parasitic lichen. All Cladonia symphycarpa samples contained a single photobiont at all three sites but Diploschistes muscorum has different algal partners at each site, changing algal partner during the transition at two sites but keeping the Cladonia photobiont at one, implying that an algal switch is not occurring at this site. This suggests that $D$. muscorum has a very flexible algal partner strategy. There is no specific photobiont which D. muscorum needs to wait for during the take-over of the host thallus, which is further supported by all these photobionts producing the same carbohydrate, ribitol (Honegger, 1991, 2012), and there is no indication that the optional algal switch influences the shift in bacterial community. Hodkinson et al., (2012) suggested that the nature of the algal partner does influence the overall composition of the bacterial communities, but they compared green algal and cyanobacterial species, respectively, which often imply completely different thallus morphologies. The existence of multiple photobionts (identified as Asterochloris irregularis and Trebouxia showmanii) in Diploschistes has been demonstrated previously by Friedl (1987), and was later molecular studies (Bačkor et al., 2010; ك̌kaloud and Peksa, 2010; Škaloud et al., 2015) have expanded the number of associated photobionts (A. glomerata, A. lobophora, and two undescribed Asterocloris species). In our study, all Asterochloris from Diploschistes and Cladonia samples group with the recently described $A$. mediterranea (Fig. S2), expanding the range of hosts of this photobiont, known only from Cladonia species (Moya et al., 2015). Earlier studies have reported Trebouxia showmanii and T. gigantea as algal partners of D. muscorum (Friedl, 1987; Friedl and Gärtner, 1988). Our Trebouxia from Diploschistes represent the undescribed 
Trebouxia "sp. URa3" (Fig. S3) which is here reported as algal partner of Diploschistes for

290 the first time. Finally, Dictyochloropsis is reported from a Diploschistes species for the first

291 time (Fig. S4). There are to our knowledge no other reports suggesting a similar generalistic

292 photobiont strategy, but there are a couple of studies on lichenicolous lichens indicating at

293 least a photobiont switch. Chaenothecopsis consociata at first associates with the host's

294 (Chaenotheca chrysocephala) Trebouxia photobiont but later replaces this with

295 Dictyochloropsis symbiontica (Tschermak-Woess, 1980). In the Rimularia insularis infection

296 of Lecanora rupicola, the Rimularia associates with the host's photobiont (de los Rios et al., 297 2002)

298 In our study, we found no evidence suggesting that the lichenicolous lichen

299 Diploschistes muscorum is specific for a host lichen with a similarly structured microbiome.

300 Instead, we observed a distinct shift of composition and pattern of variation in bacterial 301 community and photobiont association in the transition from one lichen to the other. These

302 results do not exclude that more similar communities may be observed in other cases of lichen 303 parasitism involving unrelated lichens, with more similar thallus features shared by the host 304 and its transforming parasite. The transitions seen in lichenicolous lichens suggest that these 305 symbiotic systems integrate partners with a preference for maintaining functional roles, rather 306 than particular species. Our study thus provides a promising first insight into the shifts 307 observed during lichen parasitism, which represent a symbiotic invasion process with a 308 complete reorganisation of all partners (fungi, algae, and bacteria), while the basic 309 functionalities of the lichen symbiosis remain the same: a shape-providing fungal partner, 310 carbohydrate-providing eukaryotic algae, and an associated bacterial community with 311 multiple potential functions (Grube et al., 2015). The particular functions of the bacteria, 312 however, remain to be elucidated by experimental studies in this fascinating transition of 313 bacterial communities. 


\section{Methods}

Sampling

317 Samples were collected September $9^{\text {th }} 2012$ at the Swedish Soil Crust International (SCIN)

318 site on Öland (Gynge Alvar, at $56^{\circ} 32^{\prime} 31.7^{\prime \prime} \mathrm{N}, 16^{\circ} 28^{\prime} 42.2^{\prime}$ ' $\mathrm{E}$ ), April $7^{\text {th }} 2013$ at the German

319 SCIN site (“Ruine Homburg'” at Gössenheim, Bavaria, Germany, 5001'34.8’'N, $9^{\circ} 47^{\prime} 56.1^{\prime \prime} \mathrm{E}$ ), and June $6^{\text {th }} 2013$ at an additional site on Öland (Dröstorp, at $56^{\circ} 35^{\prime} 29.7^{\prime}{ }^{\prime} N$, $\left.16^{\circ} 35^{\prime} 01.1^{\prime \prime} \mathrm{E}\right)$. All sites are on limestone bedrock with a thin gravel layer on top of the bedrock, and the vegetation is composed of a colourful lichen-dominated biological soil crust (BSC) including Cladonia spp., Diploschistes muscorum, Thamnolia vermicularis,

324 Squamarina spp., Fulgensia spp., Psora decipiens, Toninia spp., and cyanobacteria (Fig. S5).

325 Here, the dominating Cladonia species in the BSC is Cladonia symphycarpa and it is possible to follow the transition from C. symphycarpa to D. muscorum (Fig. 1A-D) at all sites. A background to the SCIN study with descriptions of the SCIN sites is given by Büdel et al. (2014). Four transition stages were sampled with three replicates on each site. The sampling was simplified by the fact that both Cladonia and Diposchistes grew in distinct, well-

330 delimited clumps or colonies, here treated as individual samples. Sampling in the field was conducted carefully avoiding contamination, and samples were kept on dry ice until arrival at

332 the laboratory, and kept at $-70{ }^{\circ} \mathrm{C}$ until processing. In the laboratory, debris and soil remnants were carefully removed before DNA extraction.

DNA extraction

336 The samples for this study were processed at two different occasions; the samples from

337 Gynge in 2012 and the samples from Dröstorp and Gössenheim in 2013. Ca.0.25g of every 338 sample was put into sterile and pyrogen free tubes, lowered into liquid $\mathrm{N}_{2}$, and ground with a 
sterile, cooled pestle. DNA extraction was done with the PowerSoil@ DNA Isolation Kit (MO

340 BIO Laboratories, Carlsbad, CA) following the manufacturer's protocol. An incubation step

341 at $70^{\circ} \mathrm{C}$ for $10 \mathrm{~min}$ was included, followed by $2 \times 30 \mathrm{sec}$ of bead beating. Each extraction

342 round included a negative control to test for contamination in the kit buffers.

16S PCR amplification and amplicon sequencing to assess bacterial community structure

345 The V4 hypervariable region of the 16S ribosomal RNA gene was amplified using GS FLX

346454 one way read barcoded fusion primers (Lib-L kit, Primer A, Primer B, Roche 454 Life

347 Science, Branford, CT, USA) with the template specific sequences F515 and R806 (Caporaso

348 et al., 2011a). PCR triplicates were run using illustra Hot Start Mix RTG beads (GE

349 Healthcare, Little Chalfont, Bucks, UK) following the manufacturer's protocol with $0.4 \mu \mathrm{M}$ of

350 each primer and $1 \mu \mathrm{L}$ of DNA extract. The PCR triplicates were pooled and purified with the

351 QiaQuick Gel Extraction kit (Qiagen, Venlo, Netherlands). After DNA quantification with

352 QuantiFluor dsDNA Dye (Promega, Madison, WI, USA) the samples were pooled equimolar

353 and were run on a 2100 Bioanalyzer (Agilent, Waldbronn, Germany) for quality assessment

354 and quantification. Emulsion PCR of pooled samples was performed with the GS Junior

355 Titanium emPCR Kit (Lib-L) (Roche 454 Life Science, Branford, CT, USA) as per the

356 manufacturer's instructions. Sequencing was run on a GS Junior instrument using GS Junior

357 Titanium Sequencing Kit and PicoTiterPlate Kit (Roche Diagnostics, Basel, Switzerland).

359 Processing of amplicon sequence data

360 Raw sequence data were pre-processed using QIIME v. 1.8.0. (Caporaso et al., 2011b).

361 Sequences were denoised (Reeder and Knight, 2010), quality-trimmed and chimeric reads

362 detected with ChimeraSlayer. Sequences were aligned using PyNAST (Caporaso et al., 2010).

363 For OTU-binning the Mothur clustering method (Schloss et al., 2009) was utilized. Sequences 
were classified using BLAST. To calculate UniFrac sample distances (Lozupone and Knight, 2005), Maximum Likelihood phylogeny was inferred with FastTree (Price et al., 2009). For QIIME downstream analyses chloroplast or mitochondria sequences were excluded, and three samples per stage were pooled and rarefied to 1,010 sequences per sample. Megan (MEtaGenome ANalyzer) was used for taxonomic comparison of samples (Huson et al., 2007). A two-sample $t$-test for alpha diversity comparison between infection stages was applied. The shared taxa (core members) across infection stages were identified using a twoparameter model and visualized with a ubiquity vs abundance plot (taxonomic ubiquity cutoff $=0.8$, abundance $=0.01)$. "Abundance" is defined as the proportion of a taxon in a sample and "ubiquity" describes the proportion of samples in which a taxon is detected (Li et al., 2013). For identification of taxa with similar occurrence patterns, a hierarchical cluster analysis was performed (Shade et al., 2013). Non-metric Multidimensional Scaling (NMDS) was used to compare sample distances and visualize clustering for both Bray-Curtis dissimilarity (OTU-based metric), and weighted and unweighted UniFrac (phylogenetic metrics) distance matrices, using the R phyloseq package (McMurdie and Holmes, 2013; R Core Team, 2013). Additional data are given in the Supporting Information.

\section{Photobiont identification}

ITS rDNA region of photobionts in transition stages A and D was amplified with primers ITS1.T and ITS4.T (Kroken and Taylor, 2000), PCR settings initial denaturation at $95^{\circ} \mathrm{C}$ for $5 \mathrm{~min}$ followed by 35 cycles of at $95^{\circ} \mathrm{C} 30 \mathrm{sec}$, annealing at $56^{\circ} \mathrm{C} 30 \mathrm{sec}$ and extension at $72^{\circ} \mathrm{C} 1 \mathrm{~min}$ with a final extension of $8 \min 72^{\circ} \mathrm{C}$. The Gynge samples in stage D resulted in PCR products of two different lengths. The PCR samples were gel-cleaned with Sigma GenElute Agarose Spin Columns (Sigma-Aldrich Inc., St Louis, USA), and reamplified. The PCR products were purified using Exonuclease I and FastAPTM Thermosensitive Alkaline 
Phosphatase (Thermo Fisher Scientific). For sequencing reactions the BigDye Terminator

390 v3.1 Cycle Sequencing Kit (Applied Biosystems, Warrington, UK) was used, following the 391 manufacturer's protocol, and fragments were separated on an ABI3130xl Genetic Analyzer

392 (Applied Biosystems). BLAST searches indicated that the 21 newly generated sequences

393 belonged to three green algal genera; Asterochloris, Trebouxia, and Dictyochloropsis (Tab.

394 S1). Three alignments were produced and a summary is present in Tab. S1. For the

395 Asterochloris alignment, sequences representing linages in Škaloud and Peksa (2010), Peksa 396 and Škaloud (2011), and Rídká et al. (2014) were selected, together with three sequences of

397 Asterochloris mediterranea. The Trebouxia alignment included a broad selection of taxa from 398 O'Brien (2014). The Dictyochloropsis alignment was based on the "Dictyochloropsis clade 2" 399 from Dal Grande et al. (2014), as this included both free-living and lichenized algae. The 400 alignments were aligned manually in AliView 1.09 (Larsson, 2014), ambiguous regions were 401 delimited manually and excluded. Evolutionary models were estimated separately for the 402 three ITS partitions (ITS1, 5.8S, and ITS2), using the Bayesian Information Criterion in 403 jMODELTEST (Posada, 2008). ML searches were run using GARLI 2.0 (Zwickl, 2006), 404 stopping after 5,000 generations if no improvement of the Ln likelihood $\leq 0.01$ was detected, 405 with a maximum of 500,000 generations. Support was assessed with 1,000 replicates of ML 406 bootstrapping under the same search models. Bayesian analyses were conducted in MrBayes 407 3.2.1 (Ronquist et al., 2012). Ten million Markov chain Monte Carlo generations were 408 sampled every $500^{\text {th }}$ step and the first $25 \%$ were discarded as burn-in. We ran two parallel 409 runs each with four chains and pooled the samples after burn-in. Mixing and convergence was 410 confirmed through the statistics provided by the program. 
As our knowledge of microbial spatial localization in lichen thalli is limited, fluorescence in

414 situ hybridization (FISH) with rRNA-targeted oligonucleotide probes is a very useful

415 technique to identify and visualize microbes and their occurrence in microhabitats without the

416 need of culturing, as it preserves the three-dimensional structure of the sample, and relates

417 spatial arrangement of organisms to substrate gradients (Amann et al., 2001). For details on

418 sample fixation, embedding, sectioning and hybridization protocol see Maier et al. (2014).

419 The oligonucleotide probes applied for hybridization were: 16S rRNA targeted 5'end-labeled

420 Cy3 (indocarbocyanine) probe EUB338 mix (an equimolar combination of EUB388,

421 EUB338II and EUB338III [Daims et al., 1999]), Cy5 (indodicarbocyanine) labelled ALF968

422 (Loy et al. 2007), Betaproteobacteria - specific FITC labelled Bet42a (Manz et al., 1992) and 423 5' end-labelled Cy5 probe Burkho (Hogardt et al., 2000). The negative controls non-EUB338 424 were 5'end-labeled with Cy3, Cy5 and FITC fluorescent dye (Wallner et al., 1993). Details on 425 the probes are given in the Tab. S2, and are available at probeBase (Loy et al., 2007). The 426 FISH assay specificity was confirmed by double-hybridizations of group-specific probes with 427 the general probes EUB. Thallus sections were observed with a Leica TCS SPE (Leica 428 Microsystem, Heidelberg, Germany) and bacteria recorded with Leica ACS APO 40x OIL CS 429 (1.15 NA) and Leica ACS APO 63x OIL CS (1.30 NA) objective lenses. The excitation 430 settings were $488 \mathrm{~nm}, 532 \mathrm{~nm}$, and $635 \mathrm{~nm}$. The wavelength ranges set to detect the emission 431 signal of the fluorochromes were fluorochrome FITC at 500-550 nm, Cy3 at 550-600 nm, 432 and Cy5 at 650-700 nm. Optical sections were taken every $1.0 \mu \mathrm{m}$ and stacked.

\section{Data deposition}

435454 FLX sff-flowgrams are deposited in the NCBI Sequence Read Archive (SRP056133).

\section{Acknowledgements}


438 This research is part of the Soil Crust INternational (SCIN) project funded by the ERA-Net

439 BiodivERsA program through The Swedish Research Council for Environment, Agricultural

440 Sciences and Spatial Planning (FORMAS) grant 226-2011-1795 and the Austrian Science

441 Foundation (FWF) grant FWF I799, as a part of the 2010-2011 BiodivERsA call. Additional

442 funding was received from the Swedish Research Council (VR) grant 621-2012-3990.

443 Grateful thanks to Dr Eje Rosén for kind advice and help on Öland. Thanks also to the Station

444 Linné, Ölands Skogsby, for helpful assistance, and to Dr Einar Timdal for Fig. 1A. Formal

445 permit for Öland was given by Länsstyrelsen, Kalmar län (dnr 521-1570-12) and at

446 Gössenheim permit was given by the District Government of Lower Franconia, Würzburg.

\section{$448 \quad$ References}

449 Amann, R.I., Fuchs, B.M., and Behrens, S. (2001) The identification of microorganisms by $450 \quad$ fluorescence in situ hybridisation. Curr Opin Biotechnol 12: 231-236.

451 Bačkor, M., Peksa, O., Škaloud, P., and Bačkorová, M. (2010) Photobiont diversity in lichens 452 from metal-rich substrata based on ITS rDNA sequences. Ecotox Environ Safe 73: 603-612.

453 Bates, S.T., Cropsey, G.W.G., Caporaso, J.G., Knight, R., and Fierer, N. (2011) Bacterial $454 \quad$ communities associated with the lichen symbiosis. Appl Environ Microbiol 77: 1309$455 \quad 1314$.

456 Boustie, J., and Grube, M. (2005) Lichens - a promising source of bioactive secondary 457 metabolites. Plant Genet Resour 3: 273-287.

458 Büdel, B., Colesie, C., Green, T.G.A., Grube, M., Lázaro Suau, R., Loewen-Schneider, K., et 459 al. (2014) Improved appreciation of the functioning and importance of biological soil 460 crusts in Europe - the Soil Crust International project (SCIN). Biodivers Conserv 23: $461 \quad 1639-1658$.

462 Cardinale, M., Vieira de Castro, J., jr., Müller, H., Berg, G., and Grube, M. (2008) In situ 

analysis of the bacteria community associated with the reindeer lichen Cladonia arbuscula reveals predominance of Alphaproteobacteria. FEMS Microbiol Ecol 66: 63-71.

Caporaso, J.G., Bittinger, K., Bushman, F.D., DeSantis, T.Z., Andersen, G.L., and Knight, R. (2010) PyNAST: a flexible tool for aligning sequences to a template alignment. Bioinformatics 26: 266-267.

Caporaso, J.G., Lauber, C.L., Walters, W.A., Berg-Lyons, D., Lozupone, C.A., Turnbaugh et al. (2011a) Global patterns of 16S rRNA diversity at a depth of millions of sequences per sample. PNAS 108: 4516-4522.

Caporaso, J.G., Kuczynski, J., Stombaugh, J., Bittinger, K., Bushman, F.D., Costello, E.K. et al. (2011b) QIIME allows analysis of high-throughput community sequencing data. Nat Methods 7: 335-336.

Daims, H., Brühl, A., Amann, R., Schleifer, K.-H., and Wagner, M. (1999) The domainspecific probe EUB338 is insufficient for the detection of all Bacteria: development and evaluation of a more comprehensive probe set. Syst Appl Microbiol 22: 434-44.

Daims, H., and Wagner, M. (2011) In situ techniques and digital image analysis methods for quantifying spatial localization patterns of nitrifiers and other microorganisms in biofilm and flocs. Methods in Enzymol 496: 185-215.

480 Dal Grande, F., Beck, A., Cornejo, C., Singh, G., Cheenacharoen, S., Nelsen, M.P., and 481 Scheidegger, C. (2014) Molecular phylogeny and symbiotic selectivity of the green algal genus Dictyochloropsis sl (Trebouxiophyceae): a polyphyletic and widespread group forming photobiont-mediated guilds in the lichen family Lobariaceae. New Phytol 202: 455-470.

de Boer, W., Folman, L.B., Summerbell, R.C., and Boddy, L. (2005) Living in a fungal world: impact of fungi on soil bacterial niche development. FEMS Microbiol Rev 29: 795-811. de los Rios, A., Ascaso, C., and Grube, M. (2002) An ultrastructural, anatomical and 
molecular study of the lichenicolous lichen Rimularia insularis. Mycol Res 106: 946-953.

489 Erlacher, A., Cernava, T., Cardinale, M., Soh, J., Sensen, C.W., Grube, M., and Berg, G.

490 (2015) Rhizobiales as functional and endosymbiontic members in the lichen symbiosis of

491 Lobaria pulmonaria L. Front Microbiol 6: 153. doi: 10.3389/fmicb.2015.00053.

492 Frey-Klett, P., Garbaye, J., and Tarkka, M. (2007) The mycorrhiza helper bacteria revisited. $493 \quad$ New Phytol 176: 22-36.

494 Frey-Klett, P., Burlinson, P., Deveau, A., Barret, M., Tarkka, M., and Sarniguet, A. (2011)

495 Bacterial-fungal interactions: hyphens between agricultural, clinical, environmental, and

496 food microbiologists. Microbiol Mol Biol Rev 75: 583-609.

497 Frey-Klett, P., and Garbaye, J. (2005) Mycorrhiza helper bacteria: a promising model for the 498 genomic analysis of fungal-bacterial interactions. New Phytol 168: 4-8.

499 Friedl, T. (1987) Thallus development and phycobionts of the parasitic lichen Diploschistes $500 \quad$ muscorum. Lichenologist 19: 183-191.

501 Friedl, T., and Gärtner, G. (1988) Trebouxia (Pleurastrales, Chlorophyta) as a phycobiont in 502 the lichen genus Diploschistes. Arch Protistenkd 135: 147-158.

503 Grube, M., Cardinale, M., Viera de Castro, J., jr., Müller, H., and Berg, G. (2009) Species504 specific structural and functional diversity of bacterial communities in lichen symbioses. 505 ISME J 3: 1105-1115.

Grube, M., Körberl, M., Lackner, S., Berg, C., and Berg, G. (2012) Host-parasite interaction and microbiome response: effects of fungal infections on the bacterial community of the Alpine lichen Solorina crocea. FEMS Microbiol Ecol 82: 472-481.

509 Grube, M., Cernava, T., Soh, J., Fuchs, S., Aschenbrenner, I., Lassek, C., et al.. (2015)

510 Exploring functional contexts of symbiotic sustain within lichen-associated bacteria by 511 comparative omics. ISME J 9: 412-424

512 Hodkinson, B.P., and Lutzoni, F. (2009) A microbiotic survey of lichen-associated bacteria 
reveals a new lineage from the Rhizobiales. Symbiosis 49: 163-180.

514 Hodkinson, B.P., Gottel, N.R., Schadt, C.W., and Lutzoni, F. (2012) Photoautotrophic symbiont and geography are major factors affecting highly structured and diverse bacterial communities in the lichen microbiome. Environ Microbiol 14: 147-161

Hogardt, M., Trebesius, K., Geiger, A.M., Hornef, M., Rosenecker, J., and Heesemann, J. (2000) Specific and rapid detection by fluorescent in situ hybridization of bacteria in clinical samples obtained from cystic fibrosis patients. J Clin Microbiol 38: 818-825.

Honegger, R. (1991) Functional aspects of the lichen symbiosis. Annu. Rev. Plant Biol. 42: $553-578$.

Honegger, R. (2012) The symbiotic phenotype of lichen-forming Ascomycetes and their endo- and epibionts. In The Mycota - A comprehensive treatise on Fungi as experimental system for basic and applied research. Fungal Association IX, 2nd edn. Esser, K. (ed). Berlin Heidelberg: Springer, pp 287-339.

Huson, D.H., Auch, A.F., Qi, J., and Schuster, S.C. (2007) MEGAN analysis of metagenomic data. Genome Res 17: 377-386.

Kroken, S., and Taylor, J.W. (2000) Phylogenetic species, reproductive mode, and specificity of the green alga Trebouxia forming lichens with the fungal genus Letharia. Bryologist 103: 645-660.

Lang, E., Swiderski, J., Stackebrandt, E., Schumann, P., Spröer, C., and Sahin, N. (2007) Herminiimonas saxobsidens sp. nov., isolated from a lichen-colonized rock. Int J Syst Evol Microbiol 57: 2618-2622.

534 Lange, O.L., Green, T.G.A., Reichenberger, H., Hesbacher, S., and Proksch, P. (1997) Do secondary substances in the thallus of a lichen promote $\mathrm{CO}_{2}$ diffusion and prevent depression of net photosynthesis at high water content? Oecologia 112: 1-3. 
539 Lawrey, J.D., and Diederich, P. (2003) Lichenicolous fungi: interactions, evolution, and $540 \quad$ biodiversity. Bryologist 106: 81-120.

541 Li, K., Bihan, M., Methé, and B.A. (2013) Analyses of the stability and core taxonomic 542 memberships of the human microbiome. PLoS ONE 8: e63139.

543 Loy, A., Maixner, F., Wagner, M., and Horn, M. (2007) probeBase:-an online resource for 544 rRNA-targeted oligonucleotide probes: new features 2007. Nucleic Acids Res 35 (suppl 1): $545 \quad$ D800-D804.

546 Lozupone, C., and Knight, R. (2005) UniFrac: a new phylogenetic method for comparing 547 microbial communities. Appl Environ Microbiol 71: 8228-8235.

548 Lücking, R., Lawrey, J.D., Sikaroodi, M., Gillevet, P.M., Chaves, J.L., Sipman, H.J.M., and 549 Bungartz, F. (2009) Do lichens domesticate photobionts like farmers domesticate crops? 550 Evidence from a previously unrecognized lineage of filamentous Cyanobacteria. Am J Bot $55196: 1409-1418$.

552 Lutzoni, F., Pagel, M., and Reeb. V. (2001) Major Fungal lineages are derived from lichen $553 \quad$ symbiotic ancestors. Nature 411: 937-940.

554 Maier, S., Schmidt, T.S.B., Zheng, L., Peer, T., Wagner, V., and Grube, M. (2014) Analyses of dryland biological soil crusts highlight lichens as an important regulator of microbial communities. Biodivers Conserv 23: 1735-1755.

Manz, W., Amann, R., Ludwig, W., Wagner, M. and Schleifer, K.-H. (1992) Phylogenetic 558 oligodeoxynucleotide probes for the major subclasses of Proteobacteria: problems and $559 \quad$ solutions. Syst Appl Microbiol 15: 593-600.

560 McMurdie, P. J., and Holmes, S. (2013) phyloseq: An R package for reproducible interactive $561 \quad$ analysis and graphics of microbiome census data. PLoS ONE 8: e61217.

562 Moya, P., Škaloud, P., Chiva, S., García-Breijo, F.J., Reig-Armiñana, J., Vancurová, L., and 
Barreno, E. (2015) Molecular phylogeny and ultrastructure of the lichen microalga Asterochloris mediterranea sp. nov. from Mediterranean and Canary Islands ecosystems. Int J Syst Evol Microbiol 65: 1838-1854.

566

Muggia, L., Klug, B., Berg, G., and Grube, M. (2013) Localization of bacteria in lichens from Alpine soil crusts by fluorescence in situ hybridization. Appl Soil Ecol 68: 20-25.

Nash, T.H. III. (2008) Lichen Biology, $2^{\text {nd }}$ ed. Cambridge, UK, Cambridge University Press.

O’Brien, H. (2014). Photobiont Diversity - Trebouxia update [WWW document]. URL www.photobiontdiversity.org/.

Peksa, O., and Škaloud, P. (2011) Do photobionts influence the ecology of lichens? A case study of environmental preferences in symbiotic green alga Asterochloris (Trebouxiophyceae). Mol Ecol 20: 3936-3948.

Piercey-Normore, M. D., DePriest, P.T. (2001) Algal switching among lichen symbioses. Am J Bot 88: 1490-1498.

Posada, D. (2008). jModelTest: phylogenetic model averaging. Mol Biol Evol 25: 1253-1256.

Price, M.N., Dehal, P.S., and Arkin, A.P. (2009) FastTree: Computing Large MinimumEvolution Trees with Profiles instead of a Distance Matrix. Mol Biol Evol 26: 1641-1650.

Printzen, C., Fernández-Mendoza, F., Muggia, L., Berg, G., and Grube, M. (2012)

Alphaproteobacterial communities in geographically distinct populations of the lichen Cetraria aculeata. FEMS Microbiol Ecol 82: 316-325.

R Core Team (2013) R: A language and environment for statistical computing. R Foundation for Statistical Computing, Vienna, Austria. URL www.R-project.org.

Rambold, G., and Triebel, D. (1992).The inter-lecanoralean associations. Bibl Lichenol 48:1-201.

Reeder, J., and Knight, R. (2010) Rapidly denoising pyrosequencing amplicon reads by exploiting rank-abundance distributions. Nat Methods 7: 668-669.

Ř́dká, T., Peksa, O., Rai, H., Upreti, D. K., and Škaloud, P. (2014) Photobiont diversity in 
Indian Cladonia lichens, with special emphasis on geographical patterns. In Terricolous lichens in India vol. 1. Rai, H., and Upreti, D. K. (eds). New York: Springer, pp. 53-71.

590 Ronquist, F., Teslenko, M., van der Mark, P., Ayres, D.L., Darling, A., Höhna, S., et al. (2012) MrBayes 3.2: efficient Bayesian phylogenetic inference and model choice across a large model space. Syst Biol 61: 539-542.

Schloss, P.D., Westcott, S.L., Ryabin, T., Hall, J.R., Hartmann, M., Hollister, E.B. et al. (2009) Introducing mothur: Open-source, platform-independent, community-supported software for describing and comparing microbial communities. Appl Environ Microbiol 75: 7537-7541.

Shade, A., McManus, P.S., and Handelsman, J. (2013) Unexpected diversity during community succession in the apple flower microbiome. MBio 4: 602-612.

Škaloud, P., and Peksa, O. (2010) Evolutionary inferences based on ITS rDNA and actin sequences reveal extensive diversity of the common lichen alga Asterochloris (Trebouxiophyceae, Chlorophyta). Mol Phylogenet Evol 54: 36-46.

Škaloud, P., Steinová, J., Ř́ídká, T., Vančurová, L., and Peksa, O. (2015) Assembling the challenging puzzle of algal biodiversity: species delimitation within the genus Asterochloris (Trebouxiophyceae, Chlorophyta). J Phycol 51: 507-527.

Tschermak-Woess, E. (1980) "Chaenothecopsis consociata - kein parasitischer oder parasymbiontischer Pilz, sondern lichenisiert mit Dictyochloropsis symbiontica, spec. nova." Plant Syst Evol 136: 287-306.

Wallner, G., Amann, R., and Beisker, W. (1993) Optimizing fluorescent in situ hybridization with rRNA-targeted oligonucleotide probes for flow cytometric identification of microorganisms. Cytometry 14: 136-143.

Webster, N.S. (2014) Cooperation, communication, and co-evolution: grand challenges in microbial symbiosis research. Front Microbiol 5: 164. 
613 Zwickl, D. J. (2006) Genetic algorithm approaches for the phylogenetic analysis of large

614 biological sequence datasets under the maximum likelihood criterion. Ph.D. dissertation, 615 The University of Texas at Austin.

616 


\section{Figure legends}

618 Fig. 1. A. Cladonia symphycarpa. B. Initial Diploschistes infection. C. Progressed

619 Diploschistes infection, with Cladonia remnants visible. D. Diploschistes muscorum. Photos:

620 A. E. Timdal, B-D. M. Westberg.

621 Fig 2. A. Bacterial community structure based on amplicon 16S rDNA data. Pie charts show 622 the proportion of reads assigned to Cladonia (grey) and Diploschistes (blue) samples (97\% 623 similarity threshold, rarefaction with a depth of 1,010 reads per sample). B. Ubiquity624 Abundance plot (family-level) with cut-offs of ubiquity $=0.8$ abundance $=0.01$. Coloured lines represent taxa above cut-offs, non-core taxa are plotted in grey, two-parameter cut-off in red.

Fig. 3. A. Network showing the number of bacterial OTUs found only in Cladonia,

627 Diploschistes or the infection stages as well as shared OTUs (based on amplicon 16S rRNA gene data; rarefaction with a depth of 1,010 reads per sample). B. Hierarchical clustering was used to determine taxa with similar occurrence patterns in the course of Diploschistesinfection. C. LEfSe results detect 16 bacterial orders with significant differential abundance.

631 Symbols: $\mathrm{A}=$ Cladonia, $\mathrm{B}=$ initial infection, $\mathrm{C}=$ progressed infection, $\mathrm{D}=$ Diploschistes .

632 Fig. 4. Bacteria colonize thalli of Cladonia and Diploschistes, visualized using fluorescence 633 in situ hybridization with confocal laser scanning microscopy (merged 3-colour images). A) and B1) Vertical section of an uninfected Cladonia squamule $(50 \mu \mathrm{m})$; Eubacteria (red) and Alphaproteobacteria (pink) in the cortex, thallus reflection (grey), algal autofluorescence (blue). B2) Enlargement of B1. C) Vertical section of an uninfected Cladonia squamule (50 $637 \mu \mathrm{m}$ ); Eubacteria (red) and Alphaproteobacteria (pink) in the lower surface, thallus reflection 638 (grey). D) Vertical section of an uninfected Cladonia squamule (50 $\mu \mathrm{m})$; Eubacteria (red), 639 Burkholderia spp. (pink) Betaproteobacteria (yellow) in the cortex, thallus reflection (grey), 640 algal autofluorescence (blue).E) Vertical section of D. muscorum thallus $(50 \mu \mathrm{m})$; Eubacteria 
641 (red), Burkholderia spp. (pink) Betaproteobacteria (yellow), thallus reflection (grey). al: algal 642 layer; co: cortex; me: medulla; ls: lower surface. Scale $=20 \mu \mathrm{m}$.

643 


\section{Supporting information}

645

646 Supplementary Methods. Processing of 454 sequence data.

647 Table S1. Voucher information, cultured algal strain or herbarium/isolate number, and

648 Genbank accession numbers of the sequences used in this study. Newly produced sequences

649 are in bold.

650 Table S2. Oligonucleotide probes used for fluorescence in situ hybridization in this study.

651 Fig. S1. Ordination using Non-Metric Multidimensional Scaling (NMDS) derived from

652 unweighted and weighted UniFrac; based on amplicon 16S rRNA gene data, rarefaction with

653 a depth of 1,010 reads per sample.

654 Fig. S2. Unrooted most likely tree of Asterochloris.

655 Fig. S3. Unrooted most likely tree of Trebouxia.

656 Fig. S4. Unrooted most likely tree of Dictyochloropsis.

657 Fig. S5. Study site at Gynge alvar, Öland, Sweden. A typical lichen-dominated biological

658 soil-crust area on limestone-pavement. Diploschistes thalli are visible as greyish clumps

659 scattered over the area. 